\title{
Influence of anthropogenic emissions on tropospheric ozone and its precursors over the Indian tropical region during a monsoon
}

\author{
Gufran Beig ${ }^{1}$ and Guy P. Brasseur ${ }^{2,3}$ \\ Received 14 October 2005; revised 21 December 2005; accepted 31 December 2005; published 8 April 2006.
}

[1] An emission inventory of ozone precursors developed for the year 1991 and 2001 is used in a Chemistry-Transport Model (MOZART) to examine the tropospheric changes in ozone and its precursors that have occurred during the 1990s in the geographical region of India in response to enhanced human activities. The maximum variation in ozone concentration near the surface is found to be around $5-10 \mathrm{ppbv}$. It reaches $5-7 \%$ in the lower part of the free troposphere and $3-5 \%$ in the upper troposphere. The maximum decadal increase in $\mathrm{CO}$ and $\mathrm{NOx}$ is about 50 70 ppbv $(10-18 \%)$ and $0.5-1.5$ ppbv $(20-50 \%)$, respectively in the boundary layer. However, in most of the troposphere, the relative magnitude reduces with height and becomes less then $5 \%$ above $10 \mathrm{~km}$. The variation in some of the volatile organic compounds is found to be significant. Citation: Beig, G., and G. P. Brasseur (2006), Influence of anthropogenic emissions on tropospheric ozone and its precursors over the Indian tropical region during a monsoon, Geophys. Res. Lett., 33, L07808, doi:10.1029/2005GL024949.

\section{Introduction}

[2] The quantification of the increasing contribution of atmospheric pollutants including nitrogen oxide $\left(\mathrm{NO}_{\mathrm{x}}\right)$, carbon monoxide $(\mathrm{CO})$, and volatile organic compounds (VOC) to global environmental changes has received much attention in recent years [Intergovernmental Panel on Climate Change (IPCC), 2001]. The estimates of anthropogenic emissions of these trace gases and their impact on the tropospheric distribution of ozone on long time scales is of great significance in that context. However, the emissions of pollutants are country-specific and systematic inventory data are rather scarce especially for the Asian region. India dominates this region in terms of population growth. This country has a high economic potential, and industrial activities as well as transportation are growing rapidly. Unlike developed, western and some Asian countries, a major source of energy in rural India (where $72 \%$ of the population resides) is bio-fuel from wood, kerosene and coal combustion. This gives rise to considerable $\mathrm{CO}$ emissions along with emissions of other source gases including $\mathrm{NO}_{\mathrm{x}}$ and VOC. The $\mathrm{CO}$ emission emitted as a result of biofuel use dominates the sources of $\mathrm{CO}$ emissions in India [Dalvi et al., 2006]. Although India's contribution to global world's $\mathrm{CO}$ emissions is merely $6 \%$, there has been a rapid

\footnotetext{
${ }^{1}$ Indian Institute of Tropical Meteorology, Pune, India.

${ }^{2}$ Max-Planck-Institut fur Meteorologie, Hamburg, Germany.

${ }^{3}$ Now at National Center for Atmospheric Research, Earth and Sun Systems Laboratory, Boulder, Colorado, USA.
}

Copyright 2006 by the American Geophysical Union. 0094-8276/06/2005GL024949\$05.00 growth in recent years [Mitra and Sharma, 2002] in contrast with the globally declining trend in $\mathrm{CO}$ level reported, for example, by Novelli [1998]. Global chemical transport models [e.g., Prather et al., 2003; Brasseur et al., 2006] suggest that surface ozone concentration could increase by as much as $25-30 \mathrm{ppbv}$ in India between years 2000 and 2100 , assuming an economic growth described by the IPCC/SRES A2 scenario. Saraf and Beig [2004] reported on the basis of ozonosonde observations at a few Indian locations that surface ozone concentrations have already increased significantly over the last 20 years. The several modeling studies that have assessed the trend in global tropospheric ozone and its precursors in response to changing emission loads [Saraf et al., 2003; Granier and Brasseur, 2003] have not discussed specifically the longterm trends and their impact in the Indian tropical region. A major source of uncertainty is the lack of systematic gridded inventory of precursor gases over the Indian region. Changing levels of ozone have implications for human health and vegetation growth. In this paper, we assess the changes in the tropospheric distribution of ozone and its precursors that may have occurred during the period from 1991 to 2001 as a result of changes in anthropogenic emissions. For this purpose, we use the MOZART-model with a new Indian inventory along with the observed winds analyzed for the fixed period.

\section{Model Description}

[3] To study the distribution of ozone and its precursors in the Indian region, we use the global chemical transport model MOZART-2 [Horowitz et al., 2003], which has a resolution of $\sim 1.8$ degrees in longitude and latitude, and includes 31 vertical levels from the surface to the pressure level of approximately $10 \mathrm{hPa}$. This model resolution allows for a description of patterns that extend over typically $200 \mathrm{~km}$, but is too coarse to provide information on smaller scale features. In all simulations, MOZART-2 is driven by assimilated meteorological data corresponding to year 1991 from the European Center for Medium Range Weather Forecasts. The model accounts for the distribution of 63 chemical species subject to 168 reactions including 33 photolysis reactions. It considers surface emissions of several chemical compounds $\left(\mathrm{CO}, \mathrm{NO}_{\mathrm{x}}, \mathrm{VOC}\right.$, etc). The emissions due to fossil fuel combustion, agricultural burning, bio-fuel, etc (except for India, see below) are taken from the recent estimates by the project named 'Precursors of Ozone and their Effect on the Troposphere' (POET) [Olivier et al., 2003]. Over the Indian subcontinent, recent high-resolution emission estimates from the Indian national inventory [Dalvi et al., 2006] account for the rapid temporal variability and small-scale geographical variations (e.g., 


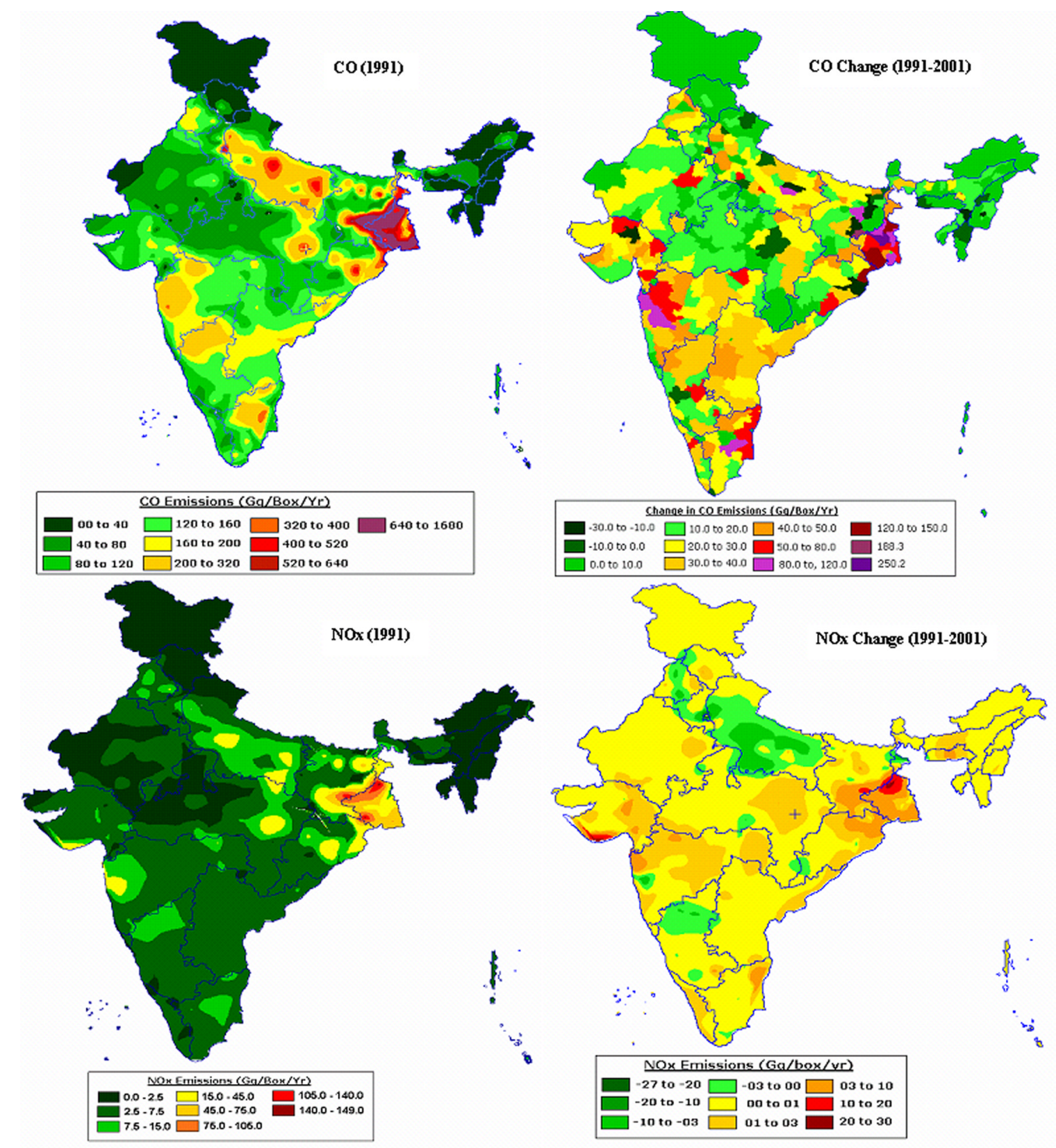

Figure 1. Gridded $\left(1^{\circ} \times 1^{\circ}\right)$ emission inventory of $\mathrm{CO}$ and NOx (in Gg NO$/$ box/yr) for the year 1991 and its departure from 2001 (change from 1991 to 2001).

hotspots). They are found to be different from the coarser estimates by global inventories like EDGAR and POET. The Indian national inventory, which is used here, considers the discrete mixture of large and modern urban populations co-existing with traditional rural and agriculture dominated populations that are found in this region of the world. Such diverse social differences are major factors that are not present in most developed countries [Garg and Shukla, 2002]. In the adopted Indian emission inventory, the CO emission for 2001 from bio-fuel sources (wood and cow dung burning) (around $34282 \mathrm{Gg} / \mathrm{yr}$ ) represents almost $50 \%$ of total $\mathrm{CO}$ emissions in India. The total $\mathrm{CO}$ emissions from all sources over the Indian region for 1991 and the absolute change $(\mathrm{Gg} / \mathrm{yr})$ per grid box of $1 \times 1^{\circ}$ from 1990 to 2001 [Dalvi et al., 2006] are shown in Figure 1. The largest emissions are found to occur in the Eastern region of India (West Bengal) where the corresponding changes in 1990's are of the order of $100 \mathrm{Gg} / \mathrm{yr}$. The location of emission hot spots seems to correlate with the densely populated rural areas, emphasizing the contribution of rural bio-fuel emissions through fuel wood burning, etc. The total $\mathrm{CO}$ emission in India $(59,300 \mathrm{Gg} / \mathrm{yr}$ in 1991 and $69,400 \mathrm{Gg} / \mathrm{yr}$ in 2001) has increased by $16 \%$ during the 1990 's, whereas the world's $\mathrm{CO}$ concentration has declined during the same period [Novelli et al., 1998]. The corresponding values in the POET inventory are slightly higher $(66,401$ and $76,942 \mathrm{Gg} / \mathrm{yr}$ respectively) with however similar rates of increase. The total surface NOx emissions in the Indian region for 1991 and 2001 are estimated to be $3500 \mathrm{Gg} \mathrm{NO} \mathrm{NO}_{2} / \mathrm{yr}$ and $4260 \mathrm{Gg} \mathrm{NO}_{2} / \mathrm{yr}$ respectively, and 
03 diff.[ppb], July 2001 wrt 1991, Newindio, $0.0 \mathrm{~km}$

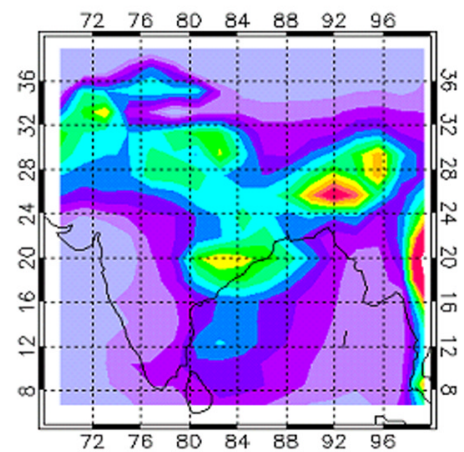

CO diff.[ppb], July 2001 wrt 1991, Newindia, $0.0 \mathrm{~km}$

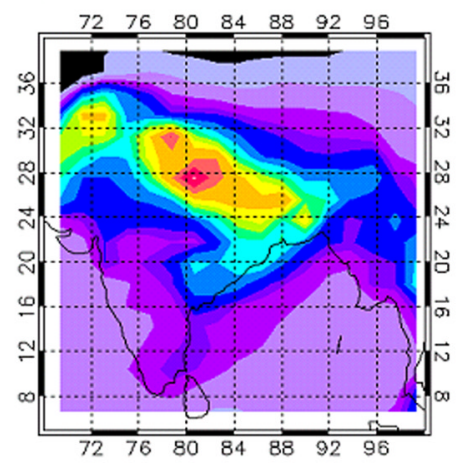

NOx diff.[ppt], July 2001 wrt 1991, Newindia, $0.0 \mathrm{~km}$

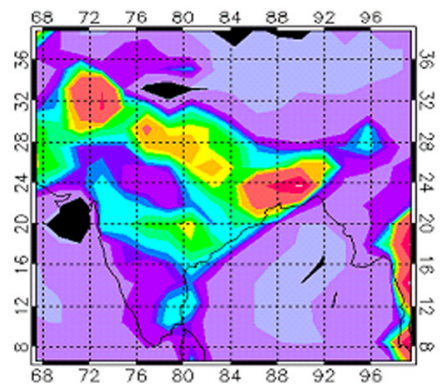

Figure 2. Model simulated change (ppbv) in ozone, $\mathrm{CO}$, and NOx, from 1991 to 2001 (July) at the surface.

have therefore increased by $22 \%$ during the 90 's. The corresponding values in the POET inventory are 5940 and $8647 \mathrm{Gg} \mathrm{NO}_{2} / \mathrm{yr}$, which corresponds to a $46 \%$ increase during the 1991 to 2001 period. The NOx emissions used here for 1991 and the absolute change (Gg/yr) from 1990 to 2001 are also shown in Figure 1. The maximum contribution is provided by coal (1540 $\mathrm{Gg} \mathrm{NO}_{2} / \mathrm{yr}$ in 1991), which amounts to about $45 \%$ of total NOx emissions in India. An increase of about $7.1 \%$ is noticed in the NOx emissions from coal during the 1990's. The second largest contribution is provided by fossil fuel combustion in 2001, which has increased dramatically (78\%) during 1990's due to rapid increase in vehicle traffic. Bio-fuel and biomass burning also contribute to NOx emissions. The location of emission hot spots (Figure 1) correlates with the location of mega cities, emphasizing the contribution of emissions through the transport sector and thermal power plants. The VOC emissions adopted in the present work are provided by the POET project. The variation between 1991 and 2000 in the emissions of some of the organic compounds (e.g., $\mathrm{C}_{2} \mathrm{H}_{6}$, acetone, $\mathrm{CH}_{2} \mathrm{O}$ ) is substantial over the Indian region whereas, according to the POET estimates, changes in the emissions of the other VOC compounds are marginal. For example, $\mathrm{C}_{2} \mathrm{H}_{6}$ emissions are found to increase by $28 \%$ from 1991 (0.371 $\mathrm{TgC} / \mathrm{yr})$ to 2001 (0.478 TgC/yr), primar-

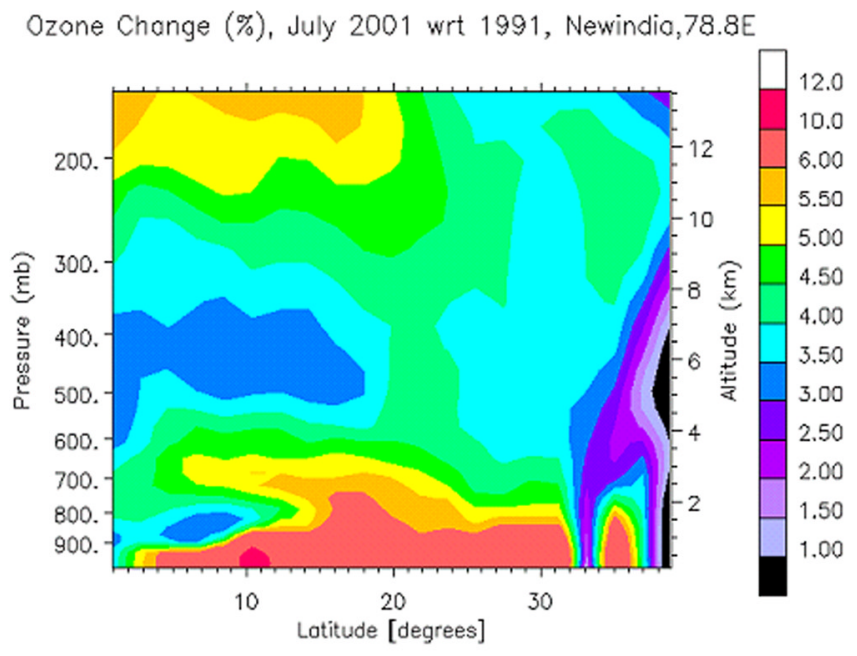

Co Change (\%), July 2001 wit 1991, Newindia, 78.8E

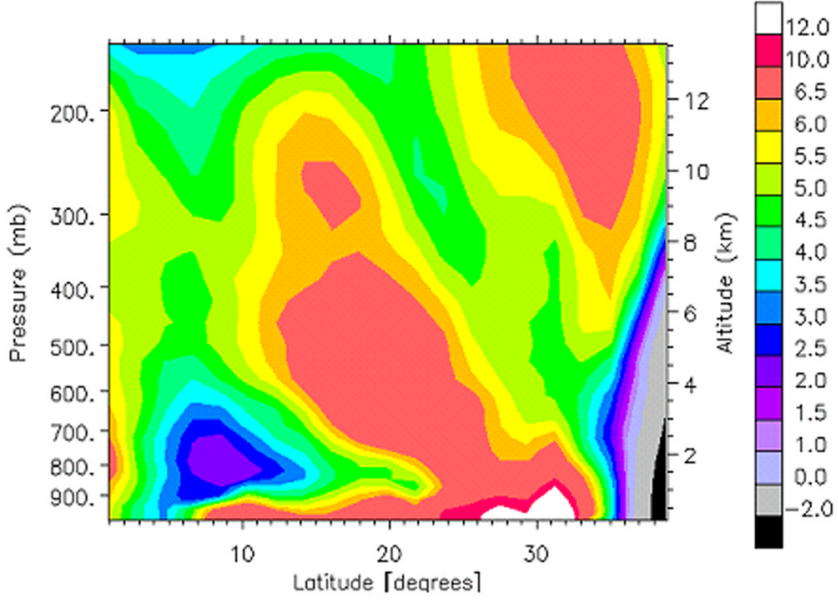

NOx Change (\%), July 2001 wrt 1991, Newindia, $78.8 E$

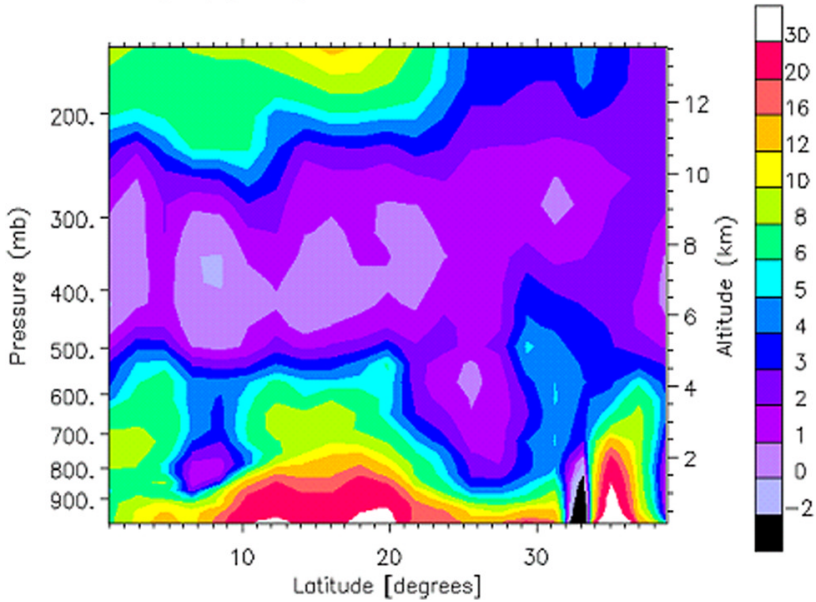

Figure 3. Vertical distribution of the percent change (\%) in ozone, $\mathrm{CO}$ and $\mathrm{NOx}$ for the latitude range $0-40^{\circ} \mathrm{N}\left(79^{\circ} \mathrm{E}\right)$ from 1991 to 2001(July). 
ily due to the increasing contribution of the transport sector. The uncertainty in the simulated (absolute) concentrations due to uncertainties in emissions is difficult to estimate, but is likely to be less then $2-5 \%$.

\section{Results}

[4] Figure 2 presents the geographical distribution in the Indian region of the relative change in the concentrations of ozone, CO, and NOx in 2001 as compared to 1991 as simulated by the MOZART model. These changes are shown near the surface for the month of July when the monsoon activity is at peak and convective activity is therefore maximum. The amount of ozone and its precursors in July are expected to be relatively low as compared to other seasons due to pronounced washout effects and surface deposition of soluble chemical species involved in the ozone budget. It is noticed from Figure 2 that the general patterns in the ozone changes are accompanied by changes in both $\mathrm{CO}$ and NOx, while the ozone hotspots are linked primarily to NOx changes. As shown in Figure 2, the increase in the ozone volume-mixing ratio is found to be $6-10 \%$ (2-4 ppbv) during 1990's in most parts of India except in West Bengal where a more substantial increase of $12-16 \%$ (5-8 ppbv) is calculated during 1990's. This maximum ozone increase is accompanied by an equally significant increase in the NOx level $(30-50 \%$ or $0.5-$ $1.5 \mathrm{ppbv}$ ) in this part of India. The absolute change in $\mathrm{CO}$ appears to be relatively high (40-60 ppbv) near the IndoGangetic plains, which corresponds to $10-20 \%$ variation. The increase in $\mathrm{CO}$ is relatively limited near the coastal regions, and, in particular, becomes negligible in the southern coastal regions of India. The pattern of ozone changes in the southern part of India and near the Indian Ocean follows the variation in NOx (Figure 2). The variations in the concentration of some volatile organic compounds are found to be significant. For example, in the Indo-Gangetic plains and eastern part of India, the change in the mixing ratio of $\mathrm{C}_{2} \mathrm{H}_{6}$ during $1990 \mathrm{~s}$ is found to be $15-30 \mathrm{ppt}$, which corresponds to a $1-2 \%$ change. It is smaller $(2-10 \mathrm{ppt})$ in Southern India. During the same period, the variation in the acetone concentration is $8-12 \%$ in Southern India and $6-8 \%$ in the central and western parts of India. The variations in the concentration of other organic compounds are marginal. Saraf and Beig [2004] have estimated the trend over the three Indian stations based on the past 30 years of ozonosonde data. For example at Trivandrum $\left(8^{\circ} \mathrm{N}\right)$, they reported a surface trend of approximately $1.4 \%$ per year, which is similar with present model results $(1.0 \%$ per year). Present results on ozone increase over India is in agreement with the model simulations of Dentener et al. [2005] using current legislation emission scenario, which reported an increase by $15 \mathrm{ppbv}$ in 30 years over the Indian subcontinent.

[5] Figure 3 shows the latitude-height distribution of the July percentage changes in the concentrations of ozone, CO and $\mathrm{NO}_{\mathrm{x}}$ in the troposphere for the Indian tropical region (fixed longitude of $79^{\circ} \mathrm{E}$ ) for 2001 as compared to 1991 . The effect of convection is clearly noticed in ozone and $\mathrm{CO}$ during July but not in NOx due to its smaller lifetime in the lower troposphere. The intense convective lifting of $\mathrm{CO}$ originating at the surface between $20-30 \mathrm{~N}$ and its gradual transport toward lower latitudes in the mid troposphere is noticed. The ozone variation in the boundary layer and its upward convective transport noticeable around $20^{\circ} \mathrm{N}$ are apparent which is largest $(9-11 \%)$ near the surface. The percentage change decreases with altitude and is found to be around $5-7 \%$ near the top of the boundary layer, and $3-5 \%$ in most parts of the middle and upper troposphere. The calculated variation in $\mathrm{CO}$ is maximum $(10-18 \%)$ in the boundary layer for the latitude range $20-30^{\circ} \mathrm{N}$. However, in most of the troposphere, the percentage change in $\mathrm{CO}$ is estimated to be $4-8 \%$. The percentage change in NOx near the surface is as large as $20-30 \%\left(10-20^{\circ} \mathrm{N}\right)$ and is rapidly decreasing with height. As in the case of ozone, the maximum built-up in NOx is found in the latitude belt of $10-20^{\circ} \mathrm{N}$. In the lower troposphere, the $\mathrm{NO}_{\mathrm{x}}$ concentration increased by $5-10 \%(3-5 \mathrm{~km})$ between 1991 and 2001 and, above the boundary layer, by less than $5 \%$. It is found that in the free troposphere the percentage change in ozone and $\mathrm{CO}$ is larger during the convectively dominated monsoon season than during the post monsoon and winter seasons. In the free troposphere, NOx does not exhibit much seasonal long-term variation due to its short photochemical lifetime. The variation in ozone and $\mathrm{CO}$ concentrations in the free troposphere is about $2-4 \%$ for the month of October and almost twice as large during the monsoon.

\section{Conclusions}

[6] Increasing chemical emissions of pollutants in the Indian tropical region during the 1990's have had a substantial impact on the concentration of tropospheric ozone at the regional scale in the boundary layer and a moderate effect in the free troposphere. Model calculations suggest that increases in ozone concentration in the 1990s were typically $2-9$ ppbv $(5-20 \%)$ in the boundary layer during July, but changes were of smaller magnitude $(3-5 \%)$ in the free troposphere. The magnitude of the variations calculated in the free troposphere during July is higher than during the post monsoon months. Perturbations in $\mathrm{CO}$ concentrations for July amount to $4-8 \%$ in 1990 's in the free troposphere but were relatively larger in the boundary layer. Changes in NOx concentrations were larger than in the case of $\mathrm{CO}$, and perturbations were less uniformly distributed near the surface. They were quite spatially uniform but with much smaller magnitude in the free troposphere. The impact of pollutants on ozone is estimated to be larger during the monsoon season extending up to the free troposphere, compared to post monsoon months due to prevailing strong convective activity in July.

[7] Acknowledgments. One of the authors (GB) acknowledge the DST, New Delhi for the assistance.

\section{References}

Brasseur, G. P., M. Schultz, C. Granier, M. Saunois, T. Diehl, M. Botzet, E. Roeckner, and S. Walters (2006), Impact of climate change on the future chemical composition of the global troposphere, J. Clim., in press.

Dalvi, M., G. Beig, U. Patil, A. Kaginalkar, C. Sharma, and A. P. Mitra (2006), A GIS based methododology for gridding large scale emission inventory: Application to carbon-monoxide emissions over Indian Region, Atmos. Environ., in press.

Dentener, F., et al. (2005), The impact of air pollutant and methane emission controls on tropospheric ozone and radiative forcing: CTM calculations for the period 1990-2030, Atmos. Chem. Phys., 5, 1731-1755. 
Garg, A., and P. R. Shukla (Eds.) (2002), Emissions Inventory of India, Tata McGraw-Hill, New Delhi, India.

Granier, C., and G. P. Brasseur (2003), The impact of road traffic on global tropospheric ozone, Geophys. Res. Lett., 30(2), 1086, doi:10.1029/ 2002GL015972.

Horowitz, L. W., et al. (2003), A global simulation of tropospheric ozone and related tracers: Description and evaluation of MOZART, version 2, J. Geophys. Res., 108(D24), 4784, doi:10.1029/2002JD002853.

Intergovernmental Panel on Climate Change (IPCC) (2001), Climate Change 2001: The Scientific Basis: Contribution of Working Group I to the Third Assessment Report of the Intergovernmental Panel on Climate Change, edited by J. T. Houghton et al., 881 pp., Cambridge Univ. Press, New York. Mitra, A. P., and C. Sharma (2002), Indian aerosols: Present status, Chemosphere, 49, 1175-1190.

Novelli, P. C., P. M. Lang, and K. A. Masarie (1998), Distributions and recent changes of carbon monoxide in the lower troposphere, J. Geophys. Res., 103, 19,015-19,033.
Olivier, J., et al. (2003), Present and future surface emissions of atmospheric compounds, POET Rep. 2, Eur. Union, Brussels.

Prather, M., et al. (2003), Fresh air in the 21 st century?, Geophys. Res. Lett., 30(2), 1100, doi:10.1029/2002GL016285.

Saraf, N., and G. Beig (2004), Long-term trends in tropospheric ozone over the Indian tropical region, Geophys. Res. Lett., 31, L05101, doi:10.1029/ 2003GL018516.

Saraf, N., G. Beig, and M. Schultz (2003), Tropospheric distribution of ozone and its precursors over the tropical Indian Ocean, J. Geophys. Res., 108(D20), 4636, doi:10.1029/2003JD003521.

G. Beig, Indian Institute of Tropical Meteorology, Pune -411008, India. (beig@tropmet.res.in)

G. P. Brasseur, National Center for Atmospheric Research, Earth and Sun Systems Laboratory, Boulder, CO 80303-3000, USA. (brasseur@ucar.edu) 